\title{
A música que soa nas escolas: contribuições de um estudo etnográfico
}

\author{
Guilherme Romanelli* \\ Universidade Federal do Paraná
}

\begin{abstract}
Resumo:
O presente artigo relata uma pesquisa etnográfica realizada em séries inicias do ensino fundamental que buscou entender a relação que as crianças estabelecem com a música dentro do cotidiano escolar. Para construir os pressupostos teóricos sobre cultura, escolarização e música, foram selecionados autores que contribuem para problematizar a função da escola na reprodução de determinadas formas culturais, e autores que apontam a possibilidade de examinar as experiências dos sujeitos na escola. Para o campo empírico, foi escolhida a etnografia como alternativa teóricometodológica para pesquisar a música na escola. São discutidos os resultados da experiência no trabalho de campo, apresentando as análises do material que foi registrado por meio da observação participante.
\end{abstract}

Palavras-chave: educação musical; ensino fundamental; etnografia.

* Guilherme Romanelli é doutor em Educação pela Universidade Federal do Paraná (UFPR), violinista, violista e professor do Departamento de Teoria e Prática de Ensino do Setor de Educação e do Programa de Pós-Graduação em Música da UFPR. 


\section{Introdução}

Com a promulgação da Lei nº 11.769 de 2008 que altera a LDB de 1996 tornando a música conteúdo obrigatório dentro da disciplina de artes, se intensificaram as discussões que já aconteciam há vários anos sobre a situação do ensino da música dentro da escola regular no Brasil. Excetuando-se as pesquisas que apresentam casos isolados de ações musicais escolares de sucesso, a maior parte da produção científica tem se concentrado na problemática da ausência da música no cotidiano da escola.

Há diversos estudos que apontam interpretações para a Lei $n^{\circ}$ 11.769/2008, indicando possíveis rumos para o novo status da música dentro da escola (ver Del Ben, 2009). Entretanto, para muitos pesquisadores e professores engajados com a volta da música nos currículos, é comum encontrar um pensamento de que o trabalho de educação musical deva ser iniciado a partir de um "marco zero", uma vez que a disciplina de música passou várias décadas ausente nos currículos brasileiros. Todavia, mesmo que a música não tenha sido contemplada oficialmente na educação básica durante um longo período, ela certamente não deixou de existir no espaço escolar.

São as indagações acima que deram origem à tese de doutorado intitulada $A$ música que soa na escola: estudo etnográfico nas séries iniciais do ensino fundamental, que teve como principal objetivo conhecer a relação que crianças das séries iniciais do ensino fundamental estabelecem com a música dentro do espaço escolar. ${ }^{1}$ Com base nos elementos levantados por essa tese, a partir do diálogo entre diversas teorias e a pesquisa de cunho etnográfico, o presente artigo tem como propósito compartilhar constatações sobre a música que ocorre na escola em situações onde não há aulas de música ou projetos extracurriculares ligados a essa linguagem artística.

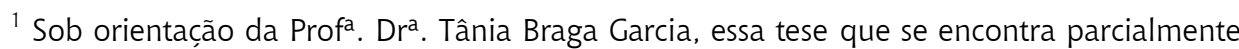
resumida neste artigo foi defendida em fevereiro de 2009. Disponível para download em $<$ http://www.ppgeufpr.pr.gov.br>.
} 


\section{Pontos de partida}

A educação musical na escola brasileira é marcada pela descontinuidade e por décadas de ausência formal enquanto componente curricular. Após o fim do Canto Orfeônico, a música na escola voltou a ser discutida na Lei nº 5.692 de 1971. Entretanto, naquela proposta a música era apenas uma das linguagens da Educação Artística que, sem ter o status de disciplina, se caracterizava principalmente como conjunto de atividades de caráter recreativo sob uma orientação nebulosa de um estímulo à livre expressão. A LDB de 1996, Lei no 9.394/1996, recolocou a arte enquanto disciplina, mas sob uma orientação polivalente. Dentro dessa nova orientação, o ensino de música se perdeu, diluído pela falta de formação específica dos professores de artes na área musical, ou em decorrência de dúvidas metodológicas no debate entre as funções essencialista e contextualista das artes no processo escolar (ver Almeida, 2001).

A partir de uma realidade conturbada para a música dentro dos estabelecimentos escolares que durou diversas décadas, em grande parte resultante da ausência de um direcionamento público sobre o ensino da música, a educação musical passa a ocupar uma multiplicidade de espaços (Souza, 2007). É

80 a partir dessa longa transformação que o acesso ao estudo de música passa a ser entendido como uma oportunidade reservada apenas àqueles herdeiros de tradição musical familiar, ou aos participantes de algum grupo social que tem a música como elemento importante, como é o caso das comunidades evangélicas, ou ainda aos financeiramente e culturalmente mais favorecidos. Tal panorama, além de culturalmente perverso, provavelmente reforçou a ideia bastante difundida pelo senso comum de que o desenvolvimento musical de um sujeito depende do seu "dom" ou talento (ver Galvão, 2007; Figueiredo e Schmidt, 2005).

O número de pesquisas sobre o ensino de música no Brasil aumentou consideravelmente nas últimas décadas como destaca Fernandes (1999 e 2007). Nessa vasta produção científica podem-se encontrar pesquisas baseadas no estudo de leis e normatizações oficiais (Bréscia, 2003; Figueiredo, 2002; Fonterrada, 2005; Hentschke e Oliveira, 2000; Penna, 2004); sobre currículos 
(Joly, 2003); baseadas em depoimento de professores (Beyer, 2003; Spanavello e Bellochio, 2005) e relatos de alunos (Del Ben, 2000a e 2000b; Ramos, 2003; Subtil, 2005 e 2006; Wolffenbüttel, 2004); sobre cursos de formação de professores (Bellochio, 2003; Figueiredo, 2005a e 2005b; Mendes e Cunha, 2001; Tozetto, 2005); e a partir do entendimento da relação cotidiano e escola (Souza, 2000a, 2000b e 2000c).

No conjunto indicado, questões fundamentais para entender como a música é ensinada foram contempladas pelos pesquisadores, incluindo diversos aspectos da relação que as crianças estabelecem com a música nos espaços escolares. No entanto, é preciso destacar que as pesquisas foram desenvolvidas por meio de abordagens metodológicas que não privilegiam, em sua maioria, a observação sistemática da relação entre a criança e a música na escola, ou seja, existe um espaço para a pergunta: O que ocorre musicalmente na escola?

Para responder essa pergunta, esta pesquisa optou pela abordagem etnográfica, que privilegia a observação participante como estratégia de trabalho de campo. Tal abordagem permitiu oferecer uma lente diferenciada para trazer subsídios ao entendimento do espaço da música no cotidiano escolar. A etnografia é uma forma de aproximação da realidade que permite verificar o que não está presente nos documentos oficiais ou nos discursos sobre as práticas escolares (Rockwell, 1987).

Essa decisão também está sustentada na constatação de que a temática tem sido tradicionalmente investigada com sustentação na área da Psicologia, como salientam Campbell (1998) e Fernandes (2007), particularmente na perspectiva do comportamentalismo. Optou-se, então, por buscar uma abordagem que permitisse o desenvolvimento da análise da relação dos alunos com a música em bases culturais. Tal decisão reflete uma escolha teóricometodológica, sem, contudo desconsiderar os avanços na pesquisa sobre o desenvolvimento musical fundamentados na área da Psicologia, como é o caso dos estudos recentemente divulgados no Brasil especialmente em torno da Associação Brasileira de Cognição e Artes Musicais, por meio de suas publicações e eventos. 
Esta pesquisa considerou que o entendimento mais aprofundado da relação que as crianças estabelecem com a música dentro da escola pode ser uma contribuição para uma educação musical significativa para os alunos, já que pouco se conhece sobre a relação criança-música na especificidade do ambiente escolar brasileiro.

A pesquisa etnográfica aqui relatada teve como foco de investigação crianças de 7 a 11 anos, por se tratar de um período em que a criança ainda não é autônoma em suas escolhas musicais e que está disponível para ouvir e gostar de uma grande variedade de estilos musicais (Hargreaves, 1995). O universo pesquisado se concentrou em escolas públicas municipais, sendo feitas cerca de cem horas de observações durante o segundo semestre de 2007. Foram feitas observações em todos os espaços e horário escolares, procurando identificar e registrar as ocasiões em que as crianças se relacionavam com música.

O planejamento de ida ao campo de pesquisa, assim como a organização dos dados recolhidos e sua posterior análise, ocorreram a partir de um constante diálogo entre pesquisas na área da etnografia (Rockwell, 1987; Campbell, 1998), referenciais teóricos ligados aos campos da cultura e sociologia (Williams, 1969; Bourdieu e Passeron, 1992; Dubet e Martuccelli, 1996; Charlot, 2000), e

82 teóricos da educação musical (Delalande, 1984; Maneveau, 2000).

\section{Cultura, educação e música}

Para Jean-Claude Forquin (1993), há uma relação íntima entre educação e cultura, já que a educação transmite um conteúdo que é genericamente classificado como cultura. Todavia, os estabelecimentos escolares não abordam a cultura de uma forma ampla e imparcialmente, sendo que o que transmitem aos seus alunos são na realidade "extratos de cultura” por conta da tradição seletiva da escola.

As ideias de Forquin sobre a seletividade do processo de transmissão cultural têm referências em Raymond Williams (1969), que faz uma análise da literatura para compreender como a noção de cultura mudou desde o final do século XIX. O autor toma a revolução industrial como marco relevante da 
transformação do mundo e da relação da sociedade com a cultura. Tal transformação é descrita por Williams como a "longa revolução", que é analisada sob o ponto de vista sócio-cultural a partir da variabilidade do termo "cultura" que assumiu diversos sentidos ao longo de todo esse tempo, assim como também ocorreu para outros conceitos a ele relacionados. O sentido do termo "arte", por exemplo, que inicialmente designava uma aptidão humana, sofreu grandes modificações até estar ligado à ideia de um produto acompanhado por um juízo de valor, mudança que abre espaço para o surgimento da figura do esteta, como aquele habilitado para emitir julgamentos sobre a arte. Outro aspecto apresentado por Williams é uma separação da arte e da vida que se herdou da tradição romântica e que estabelece uma nova relação entre a tríade arte/artista/sociedade. Entretanto, para o autor, de todos os termos por ele analisados, "cultura" é o que sofreu maior mudança durante a "longa revolução". Inicialmente entendido como um processo de maturação, o termo passa a representar as boas qualidades humanas, um sistema de vida e mesmo uma atividade para o ócio.

Raymond Williams demonstra que a arte é resultante de uma tradição seletiva da cultura, sendo que aquilo que é comumente entendido como cultura universal é consequência de processos de escolhas que incluem arquivamentos e eliminações de diversas culturas. $\mathrm{O}$ autor considera que atualmente ${ }^{2}$ coexistem quatro tipos de cultura: a cultura erudita; a cultura do cotidiano; a cultura operária e a cultura burguesa. Para ele, a "cultura de massa" não pode ser classificada como uma forma de cultura, pois é uma criação artificial utilizada em processos de dominação. Dessa forma, Williams não considera os meios de comunicação de massa um problema em si, indicando que os equívocos ocorrem quando são mal utilizados (ver Subtil, 2006; Souza 2000b). Para evitar uma polarização entre tipos de culturas distintas, Williams sugere a ideia de uma cultura comum, não no sentido de cultura igual, mas de uma cultura para uma sociedade mais igualitária que siga princípios de ensino para a autonomia onde cada sujeito possa escolher sua cultura. Essa proposta seria uma alternativa para

\footnotetext{
${ }^{2}$ A obra que é aqui tomada como referência foi originalmente escrita em 1958.
} 
um modelo escolar que reproduz uma cultura burguesa em que as possibilidades de ascensão são marcadas por casos individuais que apenas reafirmam a manutenção das desigualdades.

A tradição seletiva da escola é um dos elementos centrais da obra $A$ reprodução de Bourdieu e Passeron (1992). Para os autores, essa tradição ocorre segundo um processo no qual a ação pedagógica se torna uma violência simbólica por se fundamentar em um arbitrário cultural. Tal processo não é consciente para os personagens da escola, incluindo os professores, razão pela qual existe uma ilusão em considerar a escola como transmissora de uma "cultura universal" - forma relativamente imparcial. Bourdieu e Passeron fazem uma análise aprofundada dos personagens e mecanismos escolares e suas relações, tais como: sistema de ensino institucionalizado, ação pedagógica, autoridade escolar, autoridade pedagógica, trabalho pedagógico, violência simbólica, mesclando com o conceito de habitus, de arbitrário cultural e de cultura legítima, para demonstrar que os mecanismos que se traduzem em tradição seletiva, e consequentemente em desigualdades sociais, são complexos e geralmente ocorrem de forma velada.

Ao considerar que a seletividade dos conteúdos escolares ocorre muitas 84 vezes sem a consciência dos agentes escolares, pode-se concluir que o repertório musical que é eleito como essencial na escola também segue lógicas de seleção e exclusão. Tal panorama é um estímulo para verificar as músicas que ocorrem além dos conteúdos "conservadores" da escola, ou seja, as músicas que são difundidas entre as crianças dentro dos diversos espaços e horários escolares.

As contribuições de Forquin, Williams, Bourdieu e Passeron provocam uma nova forma de pensar como a música pode integrar os currículos escolares. Essa reflexão é especialmente interessante para o caso particular do Brasil onde a construção de diretrizes e currículos na área musical foi amplamente retomada a partir da Lei no 11.759/2008. Uma visão de relação com a música bastante comum pode ser exemplificada pelo ponto de vista de Georges Snyders (1992). Por um lado, uma das contribuições importantes desse autor é a defesa de uma escola sedutora, em que os alunos tenham prazer em se relacionar com os 
diversos saberes escolares. Entretanto, a ênfase na "alegria" que a escola pode proporcionar, como um estado de espírito diante de um determinado saber, é excessivamente montada no princípio de que existem conhecimentos "superiores", ao que chama de "obras primas". Para sua argumentação, Snyders utiliza exemplos da música como possibilidade de seduzir seus alunos a partir do contato com "obras primas". Ao dialogar especialmente com Williams, Bourdieu e Passeron, pode-se entender que a "obra prima” proposta por Snyders assume o sentido de "Cultura elaborada" e se afina, consequentemente, à ideia de uma cultura universal. Evidentemente, deve-se considerar a inegável qualidade estética de obras que foram compostas há vários séculos e que ainda seduzem por sua genialidade, mas deve-se também estar alerta para se questionar sobre tudo aquilo que é genericamente classificado dentro da ideia de cultura universal ou de "obra prima", tentando levar em conta a tradição seletiva dos processos de escolha e transmissão cultural.

O entendimento da escola enquanto instituição social conservadora de transmissão de uma cultura que é escolhida de forma arbitrária pode parecer um tanto fatalista. Para equilibrar esse ponto de vista, é possível estudar a relação com a cultura a partir do ponto de vista do próprio sujeito, ideia que Bernard Charlot (2000) desenvolve em suas pesquisas na sua teoria sobre a "relação com o saber". O autor entende a "relação com o saber" como uma forma de relação com o mundo e uma relação com o aprender, para não limitar a terminologia de saber enquanto saber-objeto. Para Charlot, não se pode entender uma relação do ambiente sobre o indivíduo de forma unidirecional e homogênea, pois existe uma relação que depende do indivíduo estar disponível para receber influências de seu meio e assimilá-las, em um processo que vai além da interiorização, ${ }^{3}$ já que assimilar pressupõe uma atitude ativa do sujeito. A contribuição de Charlot permite relativizar as determinações objetivas da sociedade sobre os sujeitos, o que abre espaço para pesquisas que têm interesse em verificar como os sujeitos se relacionam com determinados conhecimentos em seus ambientes de convivência,

\footnotetext{
${ }^{3}$ A interiorização é vista por Bourdieu e Passeron (1992) enquanto um processo passivo resultante da "inculcação" de uma ação externa, como por exemplo, uma ação pedagógica.
} 
como é o caso desta pesquisa que teve com objetivo observar crianças e suas relações com a música dentro da escola.

Outras pesquisas que colocam o sujeito enquanto personagem ativo de suas trocas culturais são encontradas em Dubet e Martuccelli (1996), que propõem uma "sociologia dos estabelecimentos escolares" e demonstram que a escola é um espaço de construção dos sujeitos, superando o sentido de simples reprodução. Dessa forma, os sujeitos são ativos na sua própria construção cultural, mesmo que esse processo ocorra de forma velada para os adultos.

A partir da presença de determinações estruturais e da constatação de que o sujeito é ativo diante de tais determinações, orienta-se para outra perspectiva de investigação: a necessidade de levar em conta as situações e os sujeitos que constroem cotidianamente a escola, e isso indica a relevância da observação participante como estratégia de trabalho de campo, e a permanência do pesquisador nesse campo como condição essencial para "abordar de modo geral as formas de existência material da escola e dar relevo ao âmbito preciso em que os sujeitos individuais, engajados na educação, experimentam, reproduzem, conhecem e transformam a realidade escolar." (Ezpeleta e Rockwell, 1989, p. 23). Com essa aproximação etnográfica da escola pretende-se responder

86 à pergunta: 0 que ocorre musicalmente na escola?

\section{A etnografia como forma de estudar a música na escola}

A escolha para o caminho teórico-metodológico desta pesquisa apontou para a "etnografia educacional" proposta pelas mexicanas Elsie Rockwell e Justa Ezpeleta como uma alternativa para entender mais profundamente a escola, cuja realidade, segundo as autoras, não se traduz apenas a partir de normas e documentos. Rockwell (1987) apresenta com detalhes os elementos que merecem uma reflexão criteriosa ao se realizar uma etnografia educacional. Configurando-se como um caminho de orientação metodológica, suas propostas incluem reflexões sobre a escolha do campo de estudo, a definição do foco de 
observação, os processos de notação e análise, o tempo de permanência em campo e as questões éticas que devem ser consideradas na ida do observador ao campo.

A etnografia se caracteriza pela observação participante, como um processo sistemático e de longa duração, como registros densos e detalhados (Garcia, 2001). Nesse processo há uma diferença entre a descrição, que deve ser a mais densa e precisa possível, e a interpretação que ocorre a partir da análise dos dados coletados e seu diálogo com a teoria. Um dos aspectos importantes sobre a etnografia é levar em conta que o pesquisador em campo não é neutro, e seu olhar não é imparcial. Isso implica em um esforço muito grande na forma de registrar e classificar as informações encontradas no campo de pesquisa.

$\mathrm{Na}$ área da música a etnografia tem sido tradicionalmente utilizada nas pesquisas ligadas à etnomusicologia. Dentre diversos autores relevantes nessa área, Tomas Turino (1999) traz reflexões sobre a necessidade do pesquisador encontrar alternativas para equívocos acadêmicos que tendem a adaptar de forma forçada o campo observado às referências científicas e culturais do pesquisador. Como proposta, o autor revisa elementos da teoria de Bourdieu, em especial sua ideia de habitus, utilizando-o como conceito de referência para entender a música. Por não envolver aspectos que não necessitam obrigatoriamente de serem verbalizados, o conceito de habitus é útil na análise de manifestações musicais. Segundo Turino, isso é importante para a etnomusicologia como uma contraposição aos estudos etnomusicológicos que se fundamentam na fala dos sujeitos observados, sendo que muitos desses sujeitos não têm o hábito de falar sobre a música, e por isso muitas vezes inventam apenas para satisfazer a busca de respostas do pesquisador, o que termina por trazer dados incoerentes sobre o universo pesquisado.

Considerando a complexidade que caracteriza o espaço escolar, a etnografia se configura enquanto alternativa importante para a pesquisa na escola, pois contempla tanto os aspectos verbais quanto não verbais da realidade observada. Para Agnes Heller, o cotidiano escolar se caracteriza como "todos os tipos de atividades que constituem, para cada sujeito 
particular, processos significativos de reprodução social e apropriação cultural" (apud Rockwell, 1995, p.7, tradução nossa).

No que se refere à etnografia ligada à pesquisa em música dentro de escolas, Patricia Campbell, (1998) apresenta um sistema de observação criado a partir da etnografia e de sistemas de notação de supervisão de estágio. A autora diferencia três momentos distintos e particulares do processo etnográfico: antes, durante e depois da ida à escola. O detalhamento de sua pesquisa inclui questões mínimas, como o tipo de bloco de anotações, até elementos comunicativos, como a forma de se apresentar aos diretores e professores da escola que se pretende pesquisar. As contribuições de Campbell foram essenciais para a realização desta pesquisa e merecem futuras comparações, uma vez que a pesquisadora realizou suas observações na América do Norte, onde as tradições sócio-culturais apresentam uma relação com a música distinta da realidade brasileira.

\section{O trabalho de campo}

Conforme as orientações de Rockwell (1987) e Campbell (1998), todo pesquisador deve iniciar sua ida ao campo de pesquisa com subsídios teóricos e proposições sobre o que observar. Dessa forma, as questões iniciais que dirigiram meu trabalho de campo se constituíram a partir de alguns princípios: da existência de outra música na escola além daquela relacionada com os professores (seja em aulas de música ou em atividades didáticas que utilizam a música de alguma forma); da consideração de que a mídia não pode ocupar o posto de único referencial musical das crianças; de que a escola apresenta uma realidade marcada por quase quarenta anos de ausência do ensino obrigatório da música.

Com um entendimento mais aprofundado sobre o campo de estudo onde seriam feitas as observações, formulei perguntas norteadoras: Onde há música no espaço escolar? Em quais momentos? Quais os elementos da mídia podem ser observados nas manifestações musicais das crianças? Quais as ideias que as crianças têm da sua própria relação com a música? Como as 
crianças aprendem música dentro da escola? Como os adultos reagem às manifestações musicais das crianças?

Como uma característica do processo etnográfico, as perguntas foram atualizadas ou reformuladas de acordo com as informações recolhidas no campo de pesquisa, como um processo de amadurecimento entre as experiências no campo e as teorias de referências, como é o exemplo da pergunta que surgiu durante as observações: Quem inicia as atividades musicais?

A aproximação com o campo empírico se deu por meio de contato com a Secretaria Municipal de Educação de Curitiba - SME que autorizou a pesquisa a partir da apresentação de um projeto que expôs os objetivos do trabalho, assim como o perfil das escolas a serem observadas. As escolas deveriam: atender crianças de 7 a 11 anos de idade, faixa etária focada por esta pesquisa; ter porte médio ou pequeno, permitindo uma aproximação com a maior parte dos sujeitos escolares; não ter professores de música ou projetos musicais, exemplificando as situações mais comuns encontradas na maioria das escolas; e estar na média dos indicativos sócio-econômicos, uma vez que não eram os objetivos da pesquisa investigar situações extremas. Com as delimitações estabelecidas, a SME contatou diversas escolas que se encaixavam nos critérios escolhidos, das quais seis manifestaram interesse em participar da pesquisa.

Em função da limitação decorrente da necessidade de realizar observações concentradas por um longo período de tempo, das seis escolas foram escolhidas duas, denominadas escola D e escola E. Ambas as escolas estão localizadas em bairros da periferia de Curitiba e atendem principalmente filhos de operários das indústrias localizadas na Cidade Industrial de Curitiba e filhos de pequenos comerciantes e profissionais liberais do bairro. A região das escolas conta com infra-estrutura urbana correta, oferecendo todos os serviços essenciais de saneamento, eletricidade, comunicação, pavimentação e transporte público.

Para cada uma das duas escolas, foi feito um contato telefônico para marcar uma primeira visita a fim de apresentar o projeto de pesquisa e esclarecer os objetivos da investigação. Esse contato foi cuidadosamente planejado, para que minha postura enquanto pesquisador fosse muito clara e franca, o que me 
permitiu a construção de laços de confiança com as duas escolas. Nas primeiras conversas, em reunião com diretores e pedagogos, expus meus focos de pesquisa evidenciando que meu interesse estava nas crianças e não na ação dos professores e outros agentes escolares. Tal esclarecimento provocou um visível alívio por parte dos representantes das escolas, muitas vezes preocupados com pesquisadores que vão à escola para fazer considerações sobre suas práticas profissionais.

Assim como a definição final das escolas, apresentada pela SME, a escolha das turmas a serem observadas não foi decidida por mim, mas pelas próprias escolas. Defini que aceitaria qualquer proposta, uma vez que os limites com os quais eu deveria trabalhar já tinham sido evidenciados por mim. Essa relativa falta de autonomia na delimitação do universo pesquisado é apontada por Rockwell (1987) como uma das características do estudo etnográfico que sempre coloca o pesquisador em situações reais e dinâmicas, o que o impossibilita de trabalhar em um ambiente controlado, como ocorre em diversas outras pesquisas cientificas. O conjunto das duas escolas me ofereceu a possibilidade de observar duas primeiras séries, duas quartas séries, uma terceira série e um primeiro ano, ${ }^{4}$ além dos horários de recreio e dias de festas. A

90 definição das turmas, que tinham uma média de 30 alunos, se deu por adesão voluntária dos professores que aceitaram que eu acompanhasse suas turmas durante todas as aulas.

Os primeiros registros foram resultado de observações gerais que tinham como principal foco o entendimento do cotidiano das crianças e suas manifestações musicais. Já nesse processo, foram esboçadas algumas categorias de análise a partir do diálogo com a teoria, o que apontou novos focos de interesse que não estavam inicialmente previstos. Durante as observações gerais, tive algumas conversas livres com alunos e professores, tanto para a construção de laços de confiança mútua, quanto para o levantamento de informações sobre as manifestações musicais na escola.

${ }^{4}$ De acordo com o novo sistema de ensino fundamental de nove anos de duração instituído pela Lei $n^{\circ} 11.274$ de 2006, o primeiro ano é ofertado em caráter obrigatório a crianças com seis anos de idade. 
Uma das preocupações da etnografia é o reconhecimento de que a observação nunca será imparcial. Entretanto, buscando uma neutralidade relativa, apoiei-me em minha calibração desenvolvida em outras pesquisas musicais a partir de fontes primárias (ver Romanelli, 2000), e enquanto músico profissional, mas sempre procurando superar o eurocentrismo da minha formação musical.

O registro de campo foi o mais discreto possível, utilizando apenas caderno, lapiseira e borracha, a fim de não chamar muita atenção com equipamentos de gravação (ver Campbell, 1998). Todas as observações utilizaram os horários em horas e minutos como indexador e sempre que necessário foram feitos desenhos de mapas e esquemas gráficos. A transcrição do caderno de notas para o computador foi feita diariamente, a fim de completar informações que eventualmente não tinham sido anotadas e preservar uma fidelidade com os acontecimentos observados (ver Rockwell, 1987; Campbell, 1998).

A minha permanência nos espaços escolares foi pautada na construção de laços de confiança com todos os personagens da escola. Sem dizer a ninguém sobre o meu foco de pesquisa (excetuando-se os professores e gestores escolares), eu assumi a postura de "alguém que quer conhecer a escola" e, conforme eu fiquei sabendo mais tarde, para os alunos, eu era um estagiário. Durante as atividades pedagógicas, sempre evitava ao máximo olhar para o professor, mesmo que algumas de suas ações fossem relevantes para minha pesquisa, a fim de evidenciar que meu foco de análise estava nas crianças e sua relação com a música e não na ação dos professores, fato que foi relevante para estreitar laços de confiança mútua. Sempre que tinha oportunidade, eu mostrava minhas anotações aos professores, dando ênfase às partituras e desenhos para exemplificar os assuntos pelos quais eu estava interessado.

Em função da complexidade do espaço escolar (ver Dubet e Martuccelli, 1996) eu registrei outros elementos que não eram necessariamente ligados à relação das crianças com a música e, em alguns momentos, extrapolei a figura de observador e me manifestei interferindo no cotidiano escolar, particularmente em situações onde presenciei algum tipo de injustiça. 
A vivacidade e a inteligência das crianças sempre me impressionaram, o que ficou evidente quando percebi que algumas crianças já me observavam desde minhas primeiras visitas, como é descrito no seguinte episódio:

Ainda no início das minhas observações na Escola Municipal D, a aluna Gabriela $^{5}$ veio me contar "Tem muito mais música lá no parquinho" (Registros de campo, segunda-feira, 24 de setembro de 2007, primeira série), referindo-se ao horário de intervalo que se aproximava. Eu fiquei muito impressionado com a observação da aluna. Ninguém além dos professores e diretores sabia que meu foco de observação era música. A menina provavelmente notou que eu anotava sempre que algo musical acontecia e ficou feliz em poder me "ajudar" em minha pesquisa. (Romanelli, 2009, p. 125).

\section{Análise etnográfica da relação das crianças com a música no espaço escolar}

A organização e análise das notas de campo demandaram a criação de categorias de análise em que fossem reagrupadas diversas situações musicais observadas que tivessem características comuns. As contribuições de outros estudos que escolheram a etnografia como alternativa teórico-metodológica para estudar a relação entre crianças e a música também foram essenciais para organizar as categorias de análise (ver Gluschankof, 2006; Campbell, 1998; Hikiji, 2006). Nesse processo evitou-se utilizar a palavra canto, pois esse quase nunca vinha isolado e incluía outros elementos não cantados. Claire Renard (1991) classifica a gama de sons que as crianças produzem com a voz e sua combinação com outros sons como "material sonoro" (p. 17, tradução nossa). Para a autora os materiais sonoros, combinados com elementos do jogo - musical ou não - são a base da invenção musical da criança.

Inicialmente divididas em oito categorias de análise, após reorganizar os registros de campo e dialogar com a teoria, foram estabelecidas três categorias principais ("expressões musicais individuais", "expressões musicais

\footnotetext{
${ }^{5}$ Todos os nomes aqui descritos são fictícios.
} 
coletivas" e "relações com o mundo adulto") que se subdividiram em outras doze, conforme a divisão a seguir:

1. Expressões musicais individuais

a. "Vinhetas musicais"
i. Sons
ii. Melodias
iii. Ritmos

b. Percepção do universo sonoro

2. Expressões musicais coletivas

a. Expressões musicais durante as aulas

b. Expressões musicais durante jogos

C. Diálogo musical

d. Aprendizagem musical entre crianças

3. Relações com o mundo adulto

a. Música e mídia

b. Reação dos adultos à música das crianças

c. Reação diante de situações musicais proporcionadas pela escola

Em todas as categorias analisadas foram encontradas manifestações musicais que apresentavam elementos essenciais para propostas de educação musical. Cada categoria reuniu um conjunto de exemplos que foram devidamente detalhados e contrapostos a teorias do campo da sociologia e da educação musical, conforme algumas transcrições a seguir.

Durante as observações, notou-se que em diversas situações a exploração de sons se iniciava a partir de uma experiência não intencional. Ao manipular algum objeto, muitos alunos acabavam fazendo algum som ao acaso que desencadeava a curiosidade e era repetido diversas vezes e explorado de diferentes formas. Segundo Pierre Schaeffer (In Delalande, 1984) o princípio da repetição e variação é o fundamento da música. Esse caso era bastante recorrente com canetas esferográficas retráteis, que produziam um som "clic" ao serem armadas e desarmadas. 
Outros sons pareciam ser produzidos intencionalmente a partir da busca de um determinado resultado sonoro interiorizado. Para Delalande (1984), essa interiorização é um projeto sonoro ativo, ao que chama "Canto interiorizado" (p. 103, tradução nossa).

[...] Ainda enquanto fazia suas dobraduras na aula de artes, o Geraldo (sete anos de idade), representando objetos voadores com seu pedaço de papel, dizia em voz alta "Parece o super-homem", e acompanhava a trajetória do papel no ar com sons da boca "Vuuuuuu" ou "Uuummm", fazendo variações de altura que iam ao agudo à medida que a mão se afastava do chão. Além da representação gestual que sugeria um determinado som, esse aluno explorava novos patamares sonoros, pois em alguns momentos, esticava o seu braço para cima até o seu limite para poder alcançar uma nota mais aguda. (Registros de campo, segunda-feira, 24 de setembro de 2007, primeira série). (Romanelli, 2009, p. 133).

Para Delalande (1984) a produção do som é um elemento ligado à possibilidade do sujeito manipular o mundo sonoro em que vive, e, portanto, provoca prazer. Durante minhas observações, a satisfação durante as explorações de som eram evidentes, pois os alunos se desligavam da aula durante a experiência, o que podia durar alguns segundos, vários minutos ou mesmo a aula inteira. Delalande também verificou crianças "esquecendo o resto [do mundo]" (p. 157, tradução nossa) quando se concentravam em suas explorações sonoras.

As experiências sonoras não se limitavam à repetição mecânica, pois muitas vezes incluíam processos elaborados de exploração sonora.

Marcelo (sete anos de idade) batia sua garrafa de água fechada e vazia como se fosse uma baqueta, produzindo três ou quatro timbres diferentes dependendo do local onde batesse: encosto da cadeira da frente, sobre a carteira e na quina da carteira. Aproveitando a elasticidade do material, explorava também as células rítmicas produzidas pelo rebote da batida e formava um ostinato que explorava dois timbres diferentes:

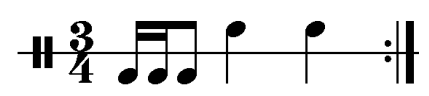


Além da célula rítmica acima o Marcelo combinou os elementos e acrescentou novas fórmulas rítmicas produzindo também:

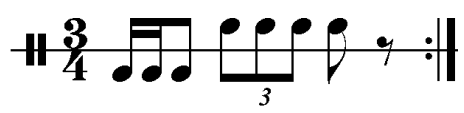

E finalmente:

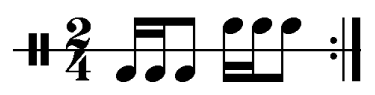

(Registros de campo, segunda-feira, 26 de novembro de 2007, primeira série) (Romanelli, 2009, p. 134).

Foi possível notar que este aluno se preocupava com a maneira de segurar a garrafa a fim de garantir o equilíbrio necessário para que o timbre e o ritmo almejados fossem produzidos. Inicialmente segurou a garrafa pelo gargalo, mas por algumas vezes também agarrou em outras partes da garrafa para encontrar o melhor ponto.

A exploração sonora feita pelo Marcelo transparecia elementos elaborados que são aprendidos em aulas de percussão e de bateria. A utilização do rebote para produzir mínimos rítmicos definidos exige um controle preciso dos movimentos que são muito sutis. A questão tímbrica também era bem privilegiada, pois o aluno certamente tinha uma ideia sonora que ele queria alcançar e que o estimulou a explorar novos sons resultantes de distintas formas de tocar.

Assim como na pesquisa de Gluschankof (2006), a exploração rítmica foi a categoria mais recorrente em minhas observações. Em muitos casos, a complexidade das células rítmicas interpretadas derrubava o mito de que crianças devem se relacionar com ritmos elementares.

Por ocasião de uma aula de educação física, uma aluna começou a fazer variantes da batida de palmas:

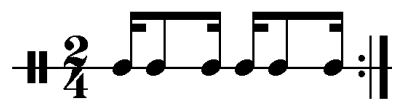

(Registros de campo, segunda-feira, 29 de outubro de 2007, primeira série). (Romanelli, 2009, p. 137). 
O exemplo rítmico acima é um ostinato sincopado que é mais frequentemente apresentado pelos professores a alunos de música que já "dominam" muito bem outras combinações rítmicas mais simples. O episódio reforça a ideia de Maneveau (2000) que se opõe ao princípio de uma "hierarquia das dificuldades na aprendizagem da 'teoria'” (p. 27, tradução nossa), em que é necessário se iniciar na música a partir de notas de longa duração.

Durante uma aula de artes, um aluno começou a bater palmas, com as duas mãos fechadas em "concha" a fim de produzir um som "fosco", com o seguinte ritmo:

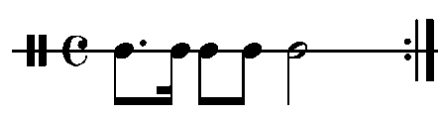

Em seguida, o mesmo ritmo foi feito com a boca "pá; pápá, pá, páaaa" e outro ritmo foi executado com palmas e com a boca "hu; huhu, hu, hu, hu, hu, hu":

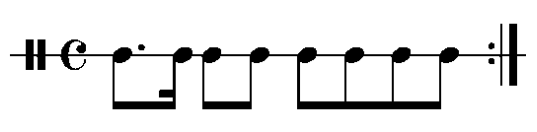

(Registros de campo, segunda-feira, 24 de setembro de 2007, primeira série) (Romanelli, 2009, p. 138).

Levando em consideração que o ouvido está permanentemente alerta ao ambiente (Schafer, 1991), as pessoas estão constantemente coletando informações sonoras do mundo que as cerca. Esse processo normalmente não é perceptível para um observador externo, já que envolve apenas a audição e a mente do ouvinte. Entretanto, em algumas situações, o estímulo sonoro do ambiente se torna evidente, quando pode-se ver o movimento do olhar de uma criança em direção à fonte sonora (ver Schafer, 1991) e especialmente quando provoca uma resposta nas crianças.

O sinal de recreio da Escola $D$ é dado por uma sirene potente que lembra os dispositivos utilizados para sinalizar as trocas de turnos de fábricas, ou os alarmes antiaéreos. Em uma ocasião em que soou o sinal para o recreio, assim que o som terminou o Aureliano (sete anos de idade) imitou a linha melódica (glissando do grave ao agudo e novamente ao grave) com um sonoro "Huummmmmm". (Registros de campo, segunda-feira, 24 de setembro de 2007, primeira série). (Romanelli, 2009, p. 139). 
Em algumas situações a percepção de sons do ambiente estimulava respostas que desencadeavam "vinhetas musicais" ou mesmo "diálogos musicais".

Em uma turma de quarta-série em um momento de relativo silêncio que marcava a leitura de um texto pela professora, foi ouvido um som repetido que parecia um martelo batendo na parede. Alguns alunos olharam para mim como se aquele som estranho pudesse ter alguma relação com a pessoa estranha à sala de aula. Assim que perceberam que eu não tinha qualquer ligação com o som, voltaram os seus olhares para os livros, ou para onde estavam olhando. A batida de martelo estava ocorrendo na sala ao lado, na parede que era comum às duas salas. Não tardou para que, em função da regularidade da batida alguns alunos começassem a responder musicalmente às batidas, percutindo os seus lápis sobre as carteiras. (Registros de campo, sexta-feira, 29 de setembro de 2007, quarta série). (Romanelli, 2009, p. 139).

Gluschankof (2006) e Campbell (1998) apresentam em suas pesquisas observações de crianças manifestando-se musicalmente durante jogos. Em diversos casos, as crianças eram observadas sozinhas, interagindo com algum brinquedo, o que era categorizado enquanto atividade musical individual. A maioria dos casos relatados nas pesquisas dessas duas autoras ocorreu com crianças de idade pré-escolar. No caso das crianças observadas nesta pesquisa, as "expressões musicais durante jogos" foram categorizadas como "expressões musicais coletivas", uma vez que quase sempre aconteceram envolvendo mais de uma criança. Nas situações em que foram observadas brincadeiras individuais envolvendo expressão musical, elas foram classificadas na categoria de "vinhetas musicais", pois sua ênfase principal geralmente estava na exploração de sons. Para uma discussão mais aprofundada entre as fronteiras entre o jogo e o jogo musical, ver Gluschankof (2006).

Durante o horário de recreio, um grupo de meninas pulava corda, sendo duas segurando a corda, e uma delas cantando e ditando o pulso. Perpendicular à corda, havia uma fila de sete crianças onde cada uma esperava sua vez para pular e sair da corda sempre que errasse, indo novamente ao final da fila.

Dentre as várias músicas, foi possível identificar ( : 80):

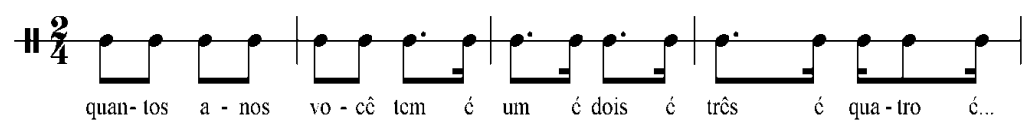


Apesar do ruído constante de crianças gritando e correndo em todas as direções, também foi possível identificar outra variante para acompanhar a brincadeira de pular corda (\rfloor$=80)$ :

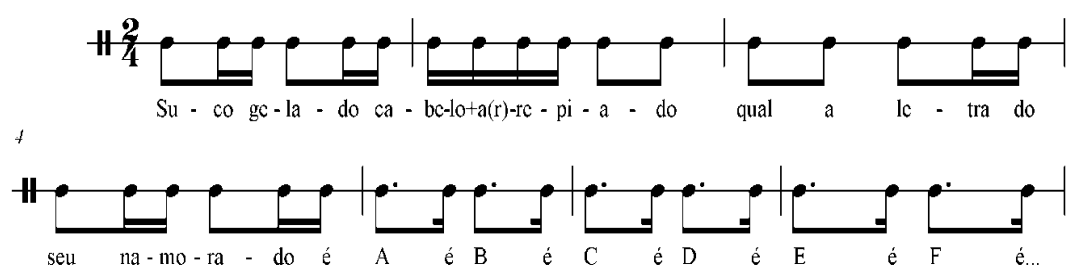

(Registros de campo, terça-feira, 18 de setembro de 2007). (Romanelli, 2009, p. 142).

De todas as manifestações musicais observadas nesta pesquisa, os jogos de pular corda pareciam os únicos a serem reconhecidos pelos alunos e pelos professores enquanto música. Além do canto ser mais evidente nessas brincadeiras, os professores da escola provavelmente percebem elementos estruturais que consideram essenciais, como uma definição de início e fim. O processo pelo qual os alunos validam sua própria produção musical segue a lógica defendida por Bourdieu e Passeron (1992) em que uma informação dos alunos só se torna autêntica quando validada pela autoridade pedagógica.

A Gabriela (sete anos de idade), que rapidamente identificou que eu estava interessado em música, me abordou um determinado recreio e me disse: "Você já sabe todas as músicas?", e começou a me cantar uma música que normalmente faz parte da brincadeira de pular corda:

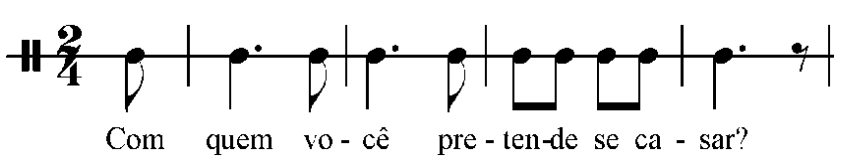

Com o final do recreio, não foi possível ouvir a música por completo. (Registros de campo, segunda-feira, 24 de setembro de 2007, primeira série). (Romanelli, 2009, p. 143).

Enquanto espaço social de trocas culturais, os diálogos musicais ocorriam de alguma forma em quase todas as "expressões musicais coletivas". Entretanto, como categoria de análise específica, foram destacados como 
"diálogos musicais" as situações em que o jogo de pergunta e resposta ocorreu diversas vezes sucessivas, a exemplo do processo de categorização utilizado por Campbell (1998).

Durante a aula de artes o Fábio (sete anos de idade) começou a cantar. Pouco tempo depois outro aluno também começou a cantar enquanto pintava, entretanto, um pouco mais forte que seu colega. Os dois cantavam melodias diferentes, mas relacionadas entre si como um jogo de pergunta e resposta. A duração das melodias era semelhante e em nenhum momento os dois alunos se olharam, o que demonstra que o diálogo entre os dois foi essencialmente musical. (Registros de campo, segunda-feira, 24 de setembro de 2007, primeira série). (Romanelli, 2009, p. 144).

Campbell (1998) descreve muitos diálogos musicais como jogos de pergunta e resposta, demonstrando que há um planejamento na resposta dada.

Logo depois da conversa, notei que o Matias cantava $(*$ = palavras que não consegui identificar):

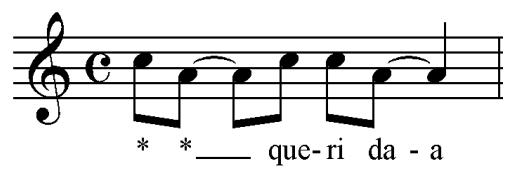

E o aluno C4 respondeu:

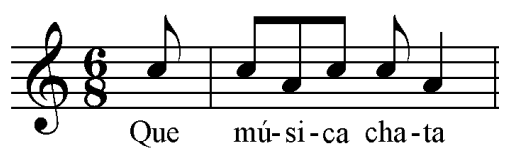

(Registros de campo, segunda-feira, 29 de outubro de 2007, primeira série). (Romanelli, 2009, p. 145).

Mesmo que em pequeno número para não extrapolar a extensão deste artigo, os exemplos apresentados dão uma ideia das inúmeras manifestações musicais que eu identifiquei nas duas escolas que visitei. O conjunto de notas de campo totalizou mais de duzentas páginas transcritas, o que demonstra a riqueza de elementos musicas que podem ser encontrados nas escolas. 


\section{Considerações finais}

Esta pesquisa teve como propósito demonstrar que a etnografia é uma forma privilegiada para estudar o cotidiano escolar, em específico para conhecer a música das crianças. Muitas manifestações musicais estudadas dificilmente seriam reveladas por outras formas de aproximação metodológica, uma vez que as crianças provavelmente não verbalizariam ou não traduziriam em conversas e entrevistas algumas de suas relações com a música.

Foi possível notar que, mesmo sem aulas de música, a cultura musical das crianças pode ser bastante elaborada. De forma alguma essa conclusão serve para diminuir a importância do ensino sistematizado de música nos diversos níveis da educação básica, mas demonstra que qualquer proposta de educação musical deve levar em conta o conhecimento musical que as crianças já possuem. O inevitável processo de didatização da música, decorrente da Lei 11.769/2008, nos coloca em uma posição de cautela em relação à escolha dos conteúdos musicais e às metodologias de ensino de música mais adequadas a cada fase escolar. Os professores devem conhecer com profundidade a música que seus alunos já fazem, evitando apenas supor a musicalidade das crianças, ou fazendo o possível

100 para não se fundamentar unicamente na memória da musicalidade da própria infância, até porque segundo Campbell (1998), a memória de infância da maioria dos adultos é "nebulosa" e não pode ser tomada como referência.

Diferentemente de outros saberes escolares, onde o conhecimento cotidiano pode trazer equívocos conceituais, como é o caso das ciências de forma geral, na educação musical o conhecimento dos alunos não se configura enquanto obstáculo epistemológico, o que significa dizer que diversas experiências musicais das crianças e sua reflexão sobre elas já podem fazer parte dos processos escolares de educação musical.

No Brasil ainda há um pensamento que condiciona a musicalidade dos sujeitos à suas qualidades natas de dom ou talento (ver Figueiredo e Schmidt, 2005; Galvão, 2007). Tais qualidades certamente não pode ser um determinante no planejamento da educação musical, já que, como esta pesquisa 
demonstrou, uma íntima relação com a música foi encontrada em praticamente todas as crianças observadas.

Nas diversas manifestações onde foi possível encontrar influência da mídia na relação das crianças com a música, notou-se que em lugar de estimular um comportamento passivo, as crianças frequentemente se apropriavam dos exemplos mediáticos e os transformavam de acordo com seus interesses, diferentemente do que normalmente se supõe quando se aborda a influência da cultura de massa (ver Subtil, 2006; Souza, 2000b).

Contrariamente ao que foi proposto por Gluschankof (2006), de acordo com os resultados desta pesquisa, não há condições mínimas para que as crianças se manifestem musicalmente. No cotidiano escolar, foram encontradas manifestações musicais em todos os momentos e espaços.

Em conversas com as crianças que já haviam me demonstrado amplamente a sua musicalidade em diversas situações, muitas delas afirmaram não saber música. Considerei tais situações como uma concepção cultural amplamente vigente do que significa saber ou não música. Para alguns daqueles alunos, saber música significava saber ler notas musicais.

Finalmente, a pesquisa demonstrou que muitos adultos que atuam na escola não notam a música das crianças, o que nos deixa, de um lado, preocupados com nossa “cegueira musical”, mas por outro, nos dá a esperança de saber que há um belíssimo universo musical a ser descoberto dentro da escola.

\section{Referências}

ALMEIDA, Célia. Concepções e práticas artísticas na escola. In: FERREIRA, Sueli (Org.). O ensino das artes: Construindo caminhos. Campinas: Papirus, 2001.

BELLOCHIO, Cláudia. Educação musical e professores dos anos iniciais de escolarização: formação inicial e práticas educativas. In: HENTSCHKE, Liane; DEL BEN, Luciana (Orgs.). Ensino de música: propostas para pensar e agir em sala de aula. São Paulo: Moderna, 2003.

BEYER, Esther. Reflexões sobre as práticas musicais na educação infantil. In: HENTSCHKE, Liane; DEL BEN, Luciana (Orgs.). Ensino de música: propostas para pensar e agir em sala de aula. São Paulo: Moderna, 2003.

BOURDIEU, Pierre; PASSERON, Jean-Claude. A reprodução. Rio de Janeiro: Francisco Alves, 1992. 
BRASIL. Lei No . 5.692, de 11 de agosto de 1971. Brasília: Ministério da Educação, 1971. - Lei no 9.394, de 20 de dezembro de 1996. Brasília: Ministério da Educação, 1996. . Lei $n^{0}$ 11.274, de 6 de fevereiro de 2006. Brasília: Ministério da Educação, 2006. . Lei $n^{\circ}$ 11.769, de 18 de agosto de 2008. Brasília: Ministério da Educação, 2008. BRÉSCIA, Vera. Educação musical: bases psicológicas e ação preventiva. Campinas: Átomo, 2003. CAMPBELL, Patricia. Songs in their heads: music and its meaning in children's lives. New York: Oxford University Press, 1998.

CHARLOT, Bernard. Da relação com o saber: elementos para uma teoria. Porto Alegre: Artes Médicas Sul, 2000.

DEL BEN, Luciana. Sobre os sentidos do ensino de música na educação básica: uma discussão a partir da Lei no 11.769/2008. Música em Perspectiva, v. 2, n. 1, p. 110-134, Curitiba, mar. 2009.

A experiência de apreciar música: relatos de alunos de $1^{\text {a }}$ série. In: SOUZA, Jusamara (Org.). Música, cotidiano e educação. Porto Alegre: UFRGS, 2000a.

- Ouvir-ver música: novos modos de vivenciar e falar sobre a música. In: SOUZA, Jusamara (Org.). Música, cotidiano e educação. Porto Alegre: UFRGS, $2000 \mathrm{~b}$.

DELALANDE, François. La musique est um jeu d'enfant. Paris: Buchet/Chastel, 1984.

DUBET, François; MARTUCCELLI, Danilo. A l'école. Sociologie de l'experience scolaire. Paris: Seuil, 1996.

EZPELETA, Justa; ROCKWELL, Elsie. Pesquisa participante. São Paulo: Cortez; Autores Associados, 1989.

FERNANDES, José Nunes. A Pesquisa em Educação Musical no Brasil - Teses e Dissertações Diversidade Temática, Teórica e Metodológica. In: Educação Musical no Brasil. Salvador: P\&A, 2007.

. Pesquisa em Educação Musical: situação do campo nas dissertações e teses dos cursos de pós-graduação stricto sensu em Educação. OPUS: Revista da Associação Nacional de Pesquisa e Pós-Graduação em Música - ANPPOM, ano 6, n. 6, p. 1-20, 1999.

FIGUEIREDO. Sérgio. Educação musical nos anos iniciais da escola: identidade e políticas educacionais. Revista da ABEM, Porto Alegre, n. 12, p. 21-30, mar. 2005a.

. Educação Musical e Pedagogia. In: SIMPÓSIO DE PESQUISA EM MÚSICA. Anais... Curitiba: DEARTES-UFPR, 2005b.

. Educação musical e os novos tempos da educação brasileira. Revista Nupeart, Florianópolis, v.1, n. 1, p. 43-58, set. 2002.

FIGUEIREDO, Sérgio; SCHMIDT, Luciana. Discutindo o talento musical. In: SIMPÓSIO DE COGNIÇÃO E ARTES MUSICAIS, 1², 2005, Curitiba. Anais... Curitiba: Deartes - UFPR, 2005.

FONTERRADA, Marisa. De tramas e fios: um ensaio sobre música e educação. São Paulo: Ed. UNESP, 2005.

FORQUIN, Jean-Claude. Escola e Cultura. Porto Alegre: Artes Médicas, 1993. 
GALVÃO, Afonso. A questão do talento: usos e abusos. In: VIRGOLIM, Angela, M. R. Talento criativo: expressão em múltiplos contextos. Brasília: Ed. UNB, 2007.

GARCIA, Tânia M. F. Braga. Origens e questões da etnografia educacional no Brasil: um balanço de teses e dissertações (1981-1998). São Paulo, 2001. Tese (Doutorado em Educação) - FEUSP, Universidade de São Paulo.

GLUSCHANKOF, Claudia. Spontaneous musical behaviors in Israeli Jewish and Arab kindergartens - searching for universal principles within cultural differences. Doctorate dissertation. Jerusalem, 2006.

HARGREAVES, David. Développement du sens artistique et musical. In: DELIÈGE, Irène; SLOBODA, John A. Naissance et développement du sens musical. Paris: Presses Universitaires de France, 1995.

HENTSCHKE, Liane; OLIVEIRA, Alda. A Educação Musical no Brasil. In: HENTSCHKE, Liane (Org.). A educação musical em países de língua neolatina. Porto Alegre: Ed. UFRGS, 2000.

HIKIJI, Rose Satiko G. A música e o risco: etnografia da performance de crianças e jovens. São Paulo: Edusp, 2006.

JOLY, Ilza. Música e educação: reflexões sobre a importância da arte nos processos educativos. In: SEMINÁRIO NACIONAL DE ARTE E EDUCAÇÃO, 17², 2003, Montenegro. Anais... Montenegro: FUNDARTE, 2003.

MANEVEAU, Guy. Musique et éducation. Aix-en-Provence: Édisud, 2000.

MENDES, Adriana; CUNHA, Glória. Um universo sonoro nos envolve. In: FERREIRA, Sueli (Org.). O ensino das artes: Construindo caminhos. Campinas: Papirus, 2001.

PENNA, Maura. A dupla dimensão da política educacional e a música na escola: II - Da legislação à prática escolar. Revista da ABEM, Porto Alegre, n. 11, p. 7-16, set. 2004.

RAMOS, Sílvia. Música da televisão no cotidiano de crianças: um estudo de caso com um grupo de 9 a 10 anos de idade. Revista da ABEM, Porto Alegre, n. 9, p. 65-60, set. 2003.

RENARD, Claire. Le Temps de /'espace. Paris: Van De Velde, 1991.

ROCKWELL, Elsie. De huellas, bardas y veredas: una historia cotidiana en la escuela. In: (Coord.). La escuela cotidiana. México, D.F.: Fondo de Cultura Económica, 1995.

. Reflexiones sobre el proceso etnografico (1982-85). Mexico: Centro de Investigación y de Estudios Avanzados del Instituto Politecnico Nacional, Departamento de Investigaciones Educativas, 1987.

ROMANELLI, Guilherme. A música que soa na escola: Estudo etnográfico nas séries iniciais do ensino fundamental. Curitiba, 2009. Tese (Doutorado em educação). Setor de Educação, Universidade Federal do Paraná.

- O carnaval de Antonina: Um estudo sobre os sambas-enredo da escola de samba

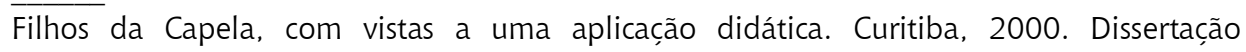
(Mestrado em educação). Setor de Educação, Universidade Federal do Paraná.

SCHAFER, Murray R. O ouvido pensante. São Paulo: Editora UNESP, 1991.

SOUZA, Jusamara. Histórias da educação musical no Brasil: à guisa de um prefácio. In: OLIVEIRA, Alda; CAJAZEIRA, Regina (Orgs.). Educação Musical no Brasil. Salvador: P\&A, 2007. 
. O cotidiano como perspectiva para a aula de música. In: SOUZA, Jusamara (Org.). Música, cotidiano e educação. Porto Alegre: UFRGS, Programa de Pós-Graduação em Música, 2000a.

. A experiência musical cotidiana e a pedagogia. In: SOUZA, Jusamara (Org.). Música, cotidiano e educação. Porto Alegre: UFRGS, Programa de Pós-Graduação em Música, 2000b.

. Educação musical e cotidiano: algumas considerações. In: SOUZA, Jusamara (Org.). Música, cotidiano e educação. Porto Alegre: UFRGS, Programa de Pós-Graduação em Música, 2000c.

SPANAVELLO, Caroline; BELLOCHIO, Cláudia. Educação musical nos anos iniciais do ensino fundamental: analisando as práticas educativas de professores unidocentes. Revista da ABEM, Porto Alegre, n. 12, p. 89-98, mar. 2005.

SUBTIL, Maria. Música midiática \& o gosto musical das crianças. Ponta Grossa: Editora UEPG, 2006.

. Mídias, música e escola: práticas musicais e representações sociais de crianças de 9

a 11 anos. Revista da ABEM, n. 13, Porto Alegre, p. 65-73, set. 2005.

TOZETTO, Henriqueta. A educação musical: a atuação do professor na educação infantil e séries iniciais. Curitiba: UTP, 2005.

TURINO, Thomas. Estrutura, contexto e estratégia na etnografia musical. Horizontes Antropológicos, Porto Alegre, ano 5, n. 11, out. 1999.

WILLIAMS, Raymond. Cultura e Sociedade 1780-1950. São Paulo: Companhia Editora Nacional, 1969.

WOLFFENBÜTTEL, Cristina. Vivências e concepções de folclore e música folclórica: um survey com alunos de 9 a 11 anos. Revista da ABEM, Porto Alegre, n. 11, p. 69-74, set. 2004.

E-mail: guilhermeromanelli@ufpr.br

Artigo recebido e aprovado em 10 de janeiro de 2010 